\title{
APOLIPOPROTEIN AV: GENE EXPRESSION, PHYSIOLOGICAL ROLE IN LIPID METABOLISM AND CLINICAL RELEVANCE
}

\author{
Xavier PRIEUR ${ }^{1,2,3}$, Thierry HUBY ${ }^{1,2}$, Joan C. RODRÍGUEZ ${ }^{4}$, Philippe COUVERT ${ }^{1,2,5}$ \\ and M. John CHAPMAN ${ }^{1,2}$
}

${ }^{1}$ INSERM U551, Dyslipoproteinemia and Atherosclerosis Research Unit, Hôpital de la Pitié, F-75013, Paris, France

${ }^{2}$ UPMC Univ Paris 06, UMR S551, F-75013, Paris, France

${ }^{3}$ GlaxoSmithKline, 25 avenue du Québec, 91951 Les Ulis cedex, France

${ }^{4}$ Department of Biochemistry and Molecular Biology, School of Pharmacy, University of Barcelona, E-08028 Barcelona, Spain.

5 AP-HP, Groupe hospitalier Pitié-Salpêtrière, Service de Biochimie endocrinienne et oncologique, F-75651 Paris cedex 13, France.

Address for Correspondence:

Dr M.J. Chapman

INSERM U.551

Pavillon Benjamin Delessert

Hôpital de la Pitié

83, Bd de l'hôpital

75651 - Paris Cedex 13

France

e-mail : chapman@chups.jussieu.fr 


\section{ABBREVIATIONS}

aa : Amino acid

Apo: apolipoprotein

CDCA: chenodeoxycholic acid

DR: direct repeat

FXR: farnesoid X-activated receptor

HDL: high-density lipoproteins

HNF- $4 \alpha$ : hepatocyte nuclear factor- $4 \alpha$

HSPG: heparan sulfate proteoglycan

LDL: low-density lipoproteins

LDLr: low-density lipoprotein receptor

LRP: LDLr-related protein

L-FABP: liver fatty acid-binding protein

LPL: lipoprotein lipase

LXR: liver X receptor

nt: nucleotide(s)

PGC-1 $\alpha$ : peroxisome proliferator-activated receptor- $\gamma$ coactivator- $1 \alpha$

PPAR $\alpha$ : peroxisome proliferator-activated receptor $\alpha$

$\mathrm{RXR}$ : retinoid $\mathrm{X}$ receptor

siRNA: small interference RNA

SNP: single nucleotide polymorphism

SREBP: sterol regulatory element binding protein

T3: 3,5,3'-triiodo-L-thyronine

TG: triglyceride

TR: thyroid hormone receptor

TRL: triglyceride-rich lipoproteins

VLDL: very low-density lipoproteins

Key words : Apolipoprotein ; hypertriglyceridemia ; Lipoprotein lipase ; TG-rich lipoproteins ; nuclear receptor ; regulation of gene expression ; fibrate ; thyroid hormone 


\section{ABSTRACT}

The apolipoprotein APOA5 gene, a member of the gene cluster on chromosome 11q23 which includes APOA1, APOC3 and APOA4, has gained considerable interest as it encodes apoAV, a key determinant of circulating levels of potentially atherogenic triglyceride-rich lipoproteins (TRL). Indeed, strong associations between genetic variants of the APOA5 gene sequence and elevated triglyceride (TG) levels have been established. This apolipoprotein may potentiate lipolysis of TRL through facilitation of lipoprotein interaction with lipoprotein lipase. In addition, apoAV may enhance clearance of remnant lipoproteins by mediating their interaction with the LDL receptor-related protein (LRP1). The implication of apoAV in intravascular TRL metabolism is further supported by studies that have demonstrated upregulation of APOA5 gene expression by nuclear receptors (PPAR $\alpha, F X R, H N F 4 \alpha$ ) and hormones (thyroxine) involved in hypotriglyceridemic pathways. APOA5 expression may equally be modulated by nutritional status, and more specifically, by stimulation of lipogenesis through transcriptional regulation mediated by insulin and SREBP-1c.

However, despite the fact that studies in mice have clearly revealed that plasma levels of apoAV are inversely correlated with plasma TG levels, the relationship between apoAV and metabolism of TRL remains controversial in man. Indeed, positive correlations between apoAV and TG levels have recently been observed in patients with hypertriglyceridemia and type 2 diabetes. The question as to whether apoAV is a key determinant of TG levels in man therefore remains conjectural. 


\section{Introduction}

The APOA5 gene encoding (apo) apolipoprotein AV was recently identified and recognized as a potential determinant of plasma triglyceride (TG) levels in mice $(1,2)$. Indeed, overexpression of human apoAV in mice leads to reduction in circulating TG concentrations, whereas the lack of apoAV is associated with hypertriglyceridemia (1). In human subjects, polymorphisms in the APOA5 gene sequence have been correlated with elevated serum TG levels in several populations (1, 3-5). By contrast, recent reports in man have documented either no correlation or alternatively a positive correlation between plasma apoAV and TG levels in hypertriglyceridemic states (6-8). It therefore remains unclear as to whether apoAV is a major modulator of circulating levels of TRL in man.

In vitro and in vivo experiments in mice support a role for apoAV in the acceleration of lipoprotein lipase (LPL)-mediated lipolysis of TG-rich lipoproteins (9-11). It is well-known that LPL is a central player in determining plasma TG levels, as LPL catalyses the hydrolysis of the hydrophobic core of TRL, including chylomicrons and VLDL. The discovery of a new plasma protein potentially implicated in the regulation of intravascular LPL activity, and probably more specifically in the postprandial state, is therefore of major significance.

Since hypertriglyceridemia is an independent risk factor for premature coronary disease (1214), and is equally a key feature of the metabolic syndrome, further understanding of the factors that regulate circulating levels of TRL may provide new opportunities for therapeutic intervention in atherogenic dyslipidemia. Indeed, apoAV is potentially implicated in the dyslipidemia of metabolic disease and, more specifically, in the hypertriglyceridemia of insulin-resistance, type 2 diabetes and metabolic syndrome.

In this review, we discuss new insights from mouse and human studies into the physiological role of apoAV, with focus on the role of this apolipoprotein in the intravascular metabolism of TRL, on the mechanisms involved in the regulation of APOA5 gene expression, and on the clinical relevance of apoAV.

\section{Identification of apoAV}

- Discovery of apoAV in 2001 as a new apolipoprotein by sequence comparison, but equally as an acute phase protein in rat.

- Biochemical property: ApoAV is a highly hydrophobic apolipoprotein. 
- Tissue distribution and synthesis of apoAV: In humans and rodents, apoA5 is produced exclusively by the liver and circulates in plasma at very low levels in association with lipoproteins.

In 2001, two groups identified the sequence of a new member of the plasma apolipoprotein family using distinct methodological approaches. By sequence comparison of human and mouse genomes, Pennacchio et al. (1) identified a conserved genomic sequence (71\% homology) that contained a putative apolipoprotein gene which was situated $30 \mathrm{~kb}$ downstream from the APOA1/C3/A4 cluster on human chromosome 11q23. In view of its homology with the APOA4 gene sequence (24\% identity and $49 \%$ similarity), the predicted 368 amino acid (aa) protein was termed apolipoprotein AV (1). At the same time, van der Vliet et al (2) identified apoAV in studies aimed at detection of new genes involved in liver regeneration in the rat following partial hepatectomy. They found that apoAV consisted of a cleavable signal peptide of 20 aa and a mature protein of 348 aa; an antibody raised against the mature protein allowed its identification as a plasma protein, which was mainly associated with HDL in the fasting state in mice.

Bioinformatic prediction and structural studies of the apoAV recombinant protein revealed a more highly hydrophobic apolipoprotein than apoAI and apoAIV, with high affinity for the lipid phase (15). In addition, apoAV presented low solubility between the $\mathrm{pH}$ limits of 3.5 and 9, a feature that may be attributed to a $\mathrm{pI}$ of 6.2 and a low percentage of charged residues (16). Secondary structure obtained by far-UV circular dichroism analysis revealed a large proportion of $\beta$-sheet, which is rather unusual for an apolipoprotein. These structural characteristics suggest tight binding of apoAV to lipoprotein lipid components. Recently, Beckstead et al (17) identified a tetraproline motif (293-296) in the C-terminal region of apoAV which modulates apoAV lipid-binding activity.

In humans and in rodents, gene expression of APOA5 appears to be hepatospecific $(2,18)$. However, this does not appear to be the case in all species, as Dichlberger et al (19) have recently reported that apoAV is also expressed in the brain, kidney, small intestine and ovarian follicles of the chicken. In mice, apoAV is secreted by the liver and circulates in the plasma in association with HDL during fasting, but shifts to VLDL in the postprandial state (9). The specific binding of apoAV to lipoprotein particles has now been confirmed in human subjects in studies involving specific immunoprecipitation of distinct lipoprotein classes, and which have demonstrated an association of apoAV with VLDL and also HDL (20). Moreover, whereas apoAV does not appear to be expressed in the intestine $(2,18)$, this apolipoprotein 
has equally been detected in chylomicrons in humans, suggesting that this association occurs in the circulation (20). Levels of apoAV in plasma are very low $(\sim 157 \mu \mathrm{g} / \mathrm{l})$ and some tenthousand fold less than that of apoAI, the major protein component of HDL (100-150 mg/dl) (20).

Implication of apoAV in triglyceride metabolism: insights from in vitro studies and mouse models

- The APOA5 KO mouse is hypertriglycerdemic whereas overexpression of apoAV reduces TG levels in murine models.

- In vivo and in vitro, apoAV induces increase in LPL activity.

- ApoAV is involved in lipoprotein uptake through its interaction with LRP1 and soRLA.

- A potential role for apoAV in hepatocyte.

The earliest data concerning the potential physiological function of apoAV revealed its implication in intravascular triglyceride metabolism in mice. Indeed, transgenic mice that overexpressed human APOA5 (1), as well as mice exhibiting adenoviral overexpression of apoAV (21), displayed marked reduction in plasma TG levels. This is in contrast to mice in which the APOA5 gene had been deleted. ApoAV-deficient mice are highly hypertriglyceridemic, with fourfold greater levels of plasma TG as compared to their wildtype littermates (1). Interestingly, the lipid profiles described above are the exact opposite of those obtained in APOC3 KO (22) and in apoCIII-overexpressing transgenic mice (23), which are respectively hypo- and hypertriglyceridemic. Indeed, apoCIII overexpression attenuates lipolysis of TRL via inhibition of LPL activity (24). These data suggest that apoAV and apoCIII, two members of the APOA1/C3/A4/A5 cluster, play antagonistic roles in the metabolism of TRL, at least in mice.

Several studies have attempted to elucidate the mechanism(s) underlying the hypotriglyceridemic effect of apoAV. Schaap et al (10) reported that adenoviral overexpression of apoAV in mice dose-dependently attenuates postprandial hypertriglyceridemia, thereby suggesting that apoAV stimulates LPL-dependent TRL clearance. Similarly, in human APOA5 transgenic mice, LPL-mediated hydrolysis was accelerated (9). Interestingly, Merkel et al (11) investigated the interplay between apoAV and LPL in vivo. Cross-breeding of APOA5 transgenic mice with hyperTG LPL+/- mice revealed 
that human apoAV diminished TG levels only moderately when LPL expression was reduced. This finding supported the notion that the effect of apoAV on plasma levels of TRL was dependent on LPL activity. Post-natal lethality of $\mathrm{LPL}^{-/-}$mice prevented investigation of the impact of hapoAV expression in the context of LPL deficiency.

In vitro, Fruchart-Najib et al (9) showed that recombinant human apoAV induces increase in LPL activity. Nonetheless, the amount of apoAV needed to activate LPL in these studies (600 $\mu \mathrm{g} / \mathrm{ml}$ ) was some 1000 -fold higher than that of the physiological human plasma concentration. Indeed, Merkel et al (11) demonstrated that recombinant human apoAV increased heparan sulfate proteoglycan (HSPG)-bound LPL activity in vitro, but had no effect on free LPL. These data suggested that apoAV accelerates TG-rich lipoprotein lipolysis by facilitating lipoprotein interaction with proteoglycan-bound LPL, leading the authors to propose that apoAV enhances the function of the natural lipolytic system as an allosteric LPL activator at the endothelial wall. Reinforcing this hypothesis, the binding of apoAV to heparin may promote the interaction of TRL with cell surface HSPG (25). Recently, it has been shown that the domain encompassing residues 192-238 of apoAV is essential for LPL activation (26). Interestingly, apoAV has been reported to interact with glycosylphosphatidylinositolanchored high-density lipoprotein-binding protein 1 (GPIHBP1) in vitro, a protein which plays a critical role in the lipolytic processing of chylomicrons. It is therefore tempting to hypothesize that apoAV could contribute to the binding of chylomicrons to GPIHBP1 (27). Taken together, in vitro and in vivo data lend support to the hypothesis that interaction between apoAV and LPL-bound HSPG is critical to enhanced LPL-mediated lipolysis of TRL (28) (Figure 1A).

In mice, apoAV deficiency resulted in attenuated removal of TG-rich lipoprotein remnants (29). Thus, VLDL particles isolated from $A P O A 5^{-/}$mice exhibited a lower affinity for the LDL receptor as compared to wild type VLDL. Recently, Nilsson et al (30) have characterized the interaction between apoAV and two members of the LDL receptor family, the LDLR-related protein 1 (LRP1) and the mosaic type-1 receptor (SorLA). These interactions involve the R210 and K211 residues of the apoAV sequence, which are equally part of the heparin binding region. The identification of these residues supports a role of apoAV in recognition of VLDL particles by members of the LDL-receptor family and thus in clearance of these particles (Figure 1A).

Taken together, the association of apoAV with heparin and proteoglycans on the one hand, and the association with LRP1 and SorLA on the other, suggest that hepatic apoAV may be secreted, after which it directly associates with HSPG on the extra-cellular surface of the 
hepatocyte plasma membrane. Therefore, we can hypothesize that apoAV may interact with other factors implicated in intravascular lipoprotein metabolism such as hepatic lipase, which is known to be cell-membrane associated. This hypothesis is of potential relevance as apoAV is partially associated with HDL during the post-prandial state, and HDL-TG are a substrate of hepatic lipase.

In view of its implication in TRL hydrolysis and clearance, it is tempting to speculate on a potential role for apoAV in the postprandial phase. Fruchart-Najib et al. (9) showed that in fasted apoA5xapoC3 transgenic mice, apoAV is preferentially associated with HDL and that in the postprandial state after a lipid bolus, apoAV shifted from HDL to VLDL. Further investigation is however required in order to provide additional insight into the potential role of apoAV in the postprandial state.

In addition to its role in TRL clearance, Schaap et al (10) suggested that apoAV may contribute to regulation of VLDL production rate. Indeed, analysis of VLDL isolated from mice 2 hours after treatment with Triton WR1339, an inhibitor of lipolysis, showed that apoAV overexpression led to reduction in both the particle size and TG content $(-26 \%)$ of VLDL. However the action of apoAV on VLDL secretion remains controversial. For instance, apoAV KO mice display a 30\% increase in VLDL particle size but no change in production rate (29). Furthermore, in the human hepatic cell line Hep3B, apoAV overexpression had no effect on apoB secretion nor on the density distribution of apoB- and apoAV-containing lipoproteins (31).

Finally, the potential role of intracellular apoAV has been addressed in in vitro cell culture studies. Thus, Weinberg et al. (15) have shown that apoB6.6F and human serum albumin are both secreted from transfected Cos- 1 cells, but not apoAV, leading the authors to propose an intracellular function for this protein. Interestingly, confocal fluorescence microscopy revealed that apoAV and apoB displayed a distinct subcellular localization pattern and a unique association of apoAV with lipid droplets in the rat hepatoma cell line, McA-RH7777 (31). These observations bring a new perspective to the potential role of apoAV in the storage and/or mobilization of intrahepatic lipids. Future studies to confirm the potential intra-cellular role of apoAV and its effect on plasma TG levels are awaited.

In summary, both in vitro and in murine models, it has been established that apoAVassociated TRL enhances TG hydrolysis through enhanced LPL activity, and that such action appears to involve binding of apoAV to HSPG at the vascular endothelium. In addition, apoAV has been proposed to enhance VLDL remnant removal by facilitating particle binding to the LDL receptor and interaction of these particles with LRP1 and SorLA. Finally, the low 
circulating levels of apoAV considered together with data from in vitro studies support an intracellular role for apoAV. Nonetheless future investigations will be critical to our understanding of the precise role(s) of apoAV in lipoprotein metabolism by the hepatocyte.

\section{Genetic variations of APOA5 and impact on TRL metabolism}

- Common polymorphisms of the APOA5 sequence are associated with high TG levels.

- Characterization of three rare point mutations in APOA5 which are associated with hypertriglyceridemia in man.

Two main types of genetic studies have been conducted on apoAV in man: firstly, those focusing on common genetic variants (single nucleotide polymorphisms) and secondly, those reporting clinical cases of patients displaying rare mutations.

With respect to common polymorphisms, several studies have demonstrated significant association between several single nucleotide polymorphisms (SNPs) in the APOA5 gene sequence and elevated serum TG levels. Among them, two common polymorphisms have been widely studied (i.e. $-1131 \mathrm{~T}>\mathrm{C}$ and c.56C $>\mathrm{G}(\mathrm{S} 19 \mathrm{~W})$ ) $(1,3)$, (reviewed in (32-34). ApoAV levels were not associated with the $-1131 \mathrm{~T}>\mathrm{C}$ SNP $(7,35)$, but have been positively correlated with elevated plasma levels of apoCIII $(35,36)$. In addition, a strong linkage disequilibrium between $-1131 \mathrm{~T}>\mathrm{C}$ and a variant for APOC3 (37) has been established. Finally, in vitro (38) and in vivo (39) studies have revealed that this SNP does not affect apoAV expression, thereby supporting the hypothesis that its association with TG levels is most probably due to the effect of the APOC3 variant with which it is in linkage disequilibrium.

The c.56C $>\mathrm{G}(\mathrm{S} 19 \mathrm{~W})$ polymorphism, which leads to an amino acid change in the region coding for the signal peptide, has been positively correlated with TG levels and, surprisingly, with apoAV levels in patients with type 2 diabetes and equally in healthy men (7). Similarly, Henneman et al. (34) have shown that there is an increased allele frequency of the minor allele of the APOA5 S19W SNP and a positive correlation with plasma apoAV and TG levels in patients with severe hypertriglyceridemia. These results seem to contradict in vitro functional studies, which suggest that the S19W polymorphism leads to a $50 \%$ decrease in apoAV secretion (38). In addition, the S19W change is associated with diminished apoAV

plasma concentrations in a transgenic mouse model (39). These findings support the hypothesis that the W19 variant reduces translocation of apoAV across the endoplasmic 
reticulum as predicted by molecular modeling. This hypothesis is not however consistent with the elevated apoAV plasma levels found in W19 carriers. Additional functional characterization appears necessary therefore in order to explain the paradox in the relationship between S19W and apoAV plasma levels. Finally, the W19 polymorphism has been positively associated with carotid intima media thickness (40) and with progression of atherosclerosis (4), findings which clearly identify our incomplete understanding of the functional impact of the $19 \mathrm{~W}$ polymorphism.

Among other polymorphisms in the APOA5 sequence, the $\mathrm{G} 182 \mathrm{C}$ variant has been associated with high TG levels in both diabetic and non diabetic cohorts (41, 42). Interestingly, a significant interaction was found between G182C and fasting glucose in the diabetic group only (42), a finding which suggests that apoAV may be implicated in the expression of a complex and multifactorial type 2 diabetic phenotype.

The functional characterization of rare APOA5 mutants has provided new insight into the physiological role of human apoAV (see ref.(43) for a review). Extrapolating from mouse models and from in vitro studies, rare mutations for APOA5 would be expected to affect TG levels through loss in LPL activity. The sequencing of DNA from 10 patients with severe hypertriglyceridemia, and in whom mutations in APOC2 or LPL were absent, led to the identification of a patient homozygous for a Q145X mutation in the APOA5 gene (renamed Q148X) (44). This mutation predicted a truncated apoAV protein devoid of key functional domains. Significantly, LPL activity in this patient was $40 \%$ lower as compared to controls; in the family, 10 individuals were heterozygous for Q148X, of whom five displayed mild hypertriglyceridemia, whereas the other five were normolipidemic. The five hypertriglyceridemic Q148X heterozygotes were also heterozygous for the S19W variant, and the homozygous patient was equally homozygous for the W19 allele. In contrast, the Q148X normolipidemic carriers displayed the S19 allele. These findings suggest that the presence of the W19 allele is required for the expression of a hypertriglyceridemic phenotype.

Marçais et al. (45) identified a heterozygous APOA5 Q139X mutation leading to production of a $15 \mathrm{kDa}$ truncated peptide of apoAV. Two families were identified: in family A, the two carriers displayed hypertriglyceridemia, and in family B, 2 carriers (of 6) were hypertriglyceridemic. Three of the hypertriglyceridemic carriers equally exhibited a marked decrease in the catabolic rate of VLDL-apoB. In addition, the hypertriglyceridemic carriers, in contrast to the normolipidemic carriers, displayed substantial impairment of LPL activity and reduction in post-heparin LPL mass. Taken together, these results lend support to the hypothesis that apoAV regulates LPL activity. Nonetheless, it should also be mentioned that 
the hypertriglyceridemic carriers in family B are heterozygous for the coding SNP S19W, whereas the normolipidemic carriers are S19 homozygotes, thereby suggesting that the W19 variant is a crucial determinant of dyslipidemia in heterozygous Q139X carriers.

Recently, Priore Oliva et al. (46) reported the case of a 17-year-old male with hypertriglyceridemia and low HDL-cholesterol levels but normal post-heparin LPL activity. The patient was homozygous for a point mutation (c.289 C>T) in the APOAV gene which resulted in transformation of a glutamine codon at position 97 into a termination codon (Q97X); apoAV was undetectable in plasma. These findings suggest that lack of apoAV has a dramatic effect on TG level without affecting post-heparin LPL activity, and support the notion that apoAV may influence LPL activity by an indirect mechanism, possibly involving complex formation with other elements such as HSPG and which are not implicated in postheparin LPL activity.

Altogether, the functional characterization of these rare mutations supports the notion that apoAV acts as an activator of TRL hydrolysis mediated by LPL. However, as remarked by Talmud et al. (43) for Q148X and Q139X mutations, the penetrance of these mutations is low and that the co-inheritance of a polymorphism in APOA5 which raises TG levels is crucial for the expression of hypertriglyceridemia.

\section{ApoAV in lipid and lipoprotein metabolism in human subjects: clinical studies}

- ApoAV and TG levels are positively correlated.

- ApoAV levels are elevated in type 2 diabetic patients in the post-prandial state.

Clinical studies have been conducted to evaluate the potential relationship between plasma levels of apoAV and TG in different pathophysiological contexts.

A positive correlation between apoAV and TG levels in the dyslipidemia of type 2 diabetes has been consistently observed. Thus, Dallinga-Thie et al. (8) found that apoAV levels, like those of apoCIII, were positively correlated with triglyceride concentrations in type 2 diabetic subjects and that the decrease in plasma TG levels following atorvastatin treatment in those subjects was correlated with reduction in apoAV. Similarly, apoAV levels were elevated in the postprandial state in type 2 diabetic subjects in contrast to healthy subjects; in addition, apoAV levels were higher in type 2 diabetic subjects in the fasting state (47). Furthermore, Schaap et al (6) documented a 5-fold increase in apoAV levels in a small population of hypertriglyceridemic patients, and observed a positive correlation between apoAV and apoCIII levels, thereby providing evidence for a complex relationship between apoAV and 
apoCIII in this phenotype. It is of note that apoAV and TG levels were not correlated in healthy subjects (6). Indeed, the authors indicated that it could be argued whether the positive correlation between TG and apoAV in type 2 diabetes was mainly due to apoCIII, as apoAV was no longer positively correlated with TG concentration after adjustment for apoCIII levels. The positive correlation between apoAV levels and TG levels is therefore established in dyslipidemic type 2 diabetic patients. To date however, there is insufficient data to ascertain as to whether increase in apoAV is a consequence of type 2 diabetes and/or hypertriglyceridemia, or whether it could be implicated in the initiation of these metabolic disorders. Additional understanding of both apoAV function and of the regulation of APOA5 expression in man is essential in this respect. Genetically-engineered human APOA5 transgenic mice could be valuable in this regard. Indeed, mice in which the APOA5 gene had been deleted, but which overexpressed the human APOA5 transgene, have been recently shown to display a positive correlation between TG and human apoAV levels (48).

A second aspect of the positive association between apoAV and TG levels involves a potential role for apoAV in the post-prandial state. As mentioned previously, apoAV levels are elevated in the post-prandial state in diabetic subjects (47). Furthermore, levels of both apoAV and apoCIII closely paralleled the postprandial triglyceride response, particularly in the VLDL1 fraction, but in contrast, did not correlate with post-heparin LPL activity (49). Finally, it has been reported that in addition to high TG levels, carriers of the $-1131 \mathrm{~T}>\mathrm{C}$ and S19W polymorphisms display modifications in post-prandial lipoprotein metabolism which includes a higher post-prandial TG level $(50,51)$. Taken together, these results clearly establish that apoAV levels are elevated after a fat load, and are positively correlated with TG levels; the physiological significance of such elevation remains indeterminate however. Future studies in the post-prandial state should be designed to further our understanding of the contribution of apoAV to post-fat load hypertriglyceridemia.

\section{APOA5 gene regulation: implication of nuclear receptors in lipid homeostasis}

- APOA5 gene expression is upregulated by PPAR $\alpha$ agonists.

- FXR, HNF-4 and ROR $\alpha$ are implicated in the regulation of APOA5 gene expression.

- ApoAV is increased by T3 and decreased in hypothyroid rats.

- APOA5 is downregulated by LXR and insulin, two activators of the expression of lipogenic genes. 
It is well established that pharmacological activation of the nuclear receptor PPAR $\alpha$ lowers plasma levels of TG-rich lipoproteins and especially those of VLDL (52-54). PPAR $\alpha$ mediates the hypotriglyceridemic effect of fibrates through activation of the transcription of genes implicated in fatty acid (FA) catabolism (55-58) and TRL clearance $(59,60)$. This latter effect has been attributed partly to stimulation of LPL activity via activation of LPL expression itself (61), but equally to a decrease in hepatic apoCIII expression $(60,62)$.

In human hepatic cells, the activation of PPAR $\alpha$ by specific agonists leads to increase in APOA5 mRNA levels $(18,63)$. In addition, 5'deletion, mutagenesis and gel-shift analyses suggest that human APOA5 gene expression is regulated by PPAR $\alpha$ through its binding to a DR1 PPAR $\alpha$ response element at $-271 \mathrm{nt}$ from the transcription start site. These studies demonstrated that the human APOA5 gene is a de facto PPAR $\alpha$ target gene (Figure 2). More recently, a 14-day treatment of cynomolgus monkeys with $0.3 \mathrm{mg} / \mathrm{kg} / \mathrm{day}$ of the PPAR $\alpha$ agonist LY570977 L-lysine revealed a 2-fold increase in apoAV plasma concentration and a $50 \%$ reduction in plasma TG levels (64). These findings demonstrate that pharmacological activation of PPAR $\alpha$ can lead to increase in plasma apoAV levels, thereby shedding new light on the molecular mechanisms which may underlie the reduction in plasma TG levels induced by PPAR $\alpha$ agonists. It can therefore be proposed that apoAV contributes to the hypotriglyceridemic effect of PPAR $\alpha$ agonists by enhancing LPL activity upon PPAR $\alpha$ activation. On the other hand, Dorfmeister et al (65) have recently demonstrated that APOA5 mRNA levels are not increased by PPAR $\alpha$ and PPAR $\gamma$ agonists in rat hepatocytes, an observation that may be explained by the lack of a functional PPAR response element in the APOA5 promoter in this species.

Recently, Lai et al. (66) compared the effects of fenofibrate treatment on APOA5 c.56G (W19) carriers and non-carriers. As previously mentioned, APOA5 c.56G carriers display higher TG levels than non-carriers before treatment; such TG levels are positively associated with apoAV concentrations. Interestingly, fenofibrate treatment enhanced both the reduction in TG and the elevation in HDL-C concentrations in the fasting state in 56G carriers versus non-carriers. In addition, differences in plasma TG and HDL-C levels observed during the postprandial response to a fat load between $56 \mathrm{C}>\mathrm{G}$ genotypes before treatment disappeared after fenofibrate intervention. The greater response of $56 \mathrm{G}$ carriers to fenofibrate could not however be explained by fenofibrate-induced APOA5 mRNA expression. Indeed, Lai et al (66) hypothesize that, by an unknown mechanism, fenofibrate may enhance TG/cholesterol exchange between VLDL and HDL, thereby leading to decrease in the TG load carried by 
VLDL. The authors therefore suggested that under conditions of fenofibrate-mediated reduction in TG levels, both the $19 \mathrm{~W}$ and $19 \mathrm{~S}$ apoAV variants might exert similar activities. These findings provide potentially new and interesting insight into the mechanism of action of fibrates.

The nuclear receptor FXR is equally implicated in TG metabolism. Even though FXR has been primarily identified as a bile acid-activated nuclear receptor involved in bile acid metabolism, it is equally a key regulator of plasma TG homeostasis. In mice, pharmacological activation of FXR by the synthetic FXR activator GW4064 or one of its natural ligands, cholic acid, led to a 50\% reduction in plasma TG levels (67). We reported that human APOA5 promoter activity is increased by FXR when activated by CDCA or GW4064 (18). Sitedirected mutagenesis and gel-shift analysis demonstrated that the APOA5 promoter responds to bile acids and FXR via a novel element consisting of an inverted repeat separated by $8 \mathrm{nt}$ (IR8) (Figure 2). Furthermore, the APOA5 IR8 element could confer responsiveness to heterologous promoters. However, no significant induction of APOA5 mRNA levels was observed by either CDCA or GW4064 in human hepatocytes. This paradox might be explained by the effect of other response elements which were not present in the 5 ' flanking region of the APOA5 gene $(-2455$ to +18$)$ selected for the study, or alternatively by posttranscriptional mechanisms. Nevertheless, Stedman et al. (68) have recently shown that bile duct ligation in mice, which raises endogenous bile acid levels, equally increases APOA5 mRNA levels in wild-type mice, whereas it decreases apoAV expression 6-fold in FXR KO mice. Moreover, FXR activation by elevated bile acid levels promotes liver regeneration (69). Given the appreciable up-regulation of APOA5 gene expression after partial hepatectomy (2), study of the potential effect of bile acid signaling on apoAV expression during liver regeneration would be of considerable interest.

HNF-4 $\alpha$ is a nuclear receptor which controls the expression of APOA1, APOC3 and APOA4 mainly through a common enhancer located 590 to 790 nucleotides upstream of the APOC3 gene (70). Similarly, HNF-4 appears to regulate human APOA5 expression through the DR1 and the IR8 elements present in the gene promoter (71). Inhibition of HNF-4 $\alpha$ expression by small interfering RNA resulted in down-regulation of apoAV (71). In addition, the peroxisome proliferator-activated receptor- $\gamma$ coactivator- $1 \alpha$ is capable of stimulating HNF$4 \alpha$-dependent transactivation of the APOA5 promoter. Furthermore, both AMP-activated protein kinase and the MAPK signaling pathway, which are well known regulators of HNF-4 protein levels, also modulate human APOA5 expression. These findings support a major role 
of HNF-4 in the regulation of the expression of the APOA1/C3/A4/A5 gene cluster. In addition to $\mathrm{HNF}-4$, an additional nuclear receptor, $\mathrm{ROR} \alpha$, can regulate APOA5 gene expression through the DR1 motif $(72,73)$ (Figure2). Such observations suggest a new mechanism by which ROR $\alpha$ may be implicated in the regulation of apolipoprotein gene expression and as a consequence, lipid metabolism.

The expression level of apoAV is upregulated by hypotriglyceridemic pathways, but it is also repressed by lipogenic pathways. Indeed, Jakel et al (74) demonstrated that a synthetic LXR agonist, T0901317, decreased APOA5 mRNA levels in HepG2 and HuH7 cells. In addition, promoter analysis showed that APOA5 promoter activity is directly regulated by SREBP1-c, a target of LXR, but not by LXR itself. SREBP-1c is a basic-helix-loop-helix-leucine zipper transcription factor involved in TG metabolism that activates lipogenic enzymes such as fatty acid synthase, SCD-1, and acyl-CoA synthase in the liver (74-76). Jakel et al. (74) identified two E-box response elements for SREBP at $+10 /+15$ and at $-76 /-81$ in the APOA5 gene (Figure 2). These authors showed that SREBP-1c represses apoAV transcription through binding to the +10 E-box of the human APOA5 gene sequence. When treated with T0901317, APOA5 transgenic mice displayed an increase in TG levels and a reduction in APOA5 mRNA concentrations. These findings allowed the authors to formulate the hypothesis that repression of apoAV expression by SREBP-1c could contribute to the hypertriglyceridemic effect of SREBP-1c activation. Furthermore, as SREBP-1c activation is modulated by nutritional status, then repression of apoAV expression by SREBP-1c could provide a link between apoAV level and nutritional state.

Insulin, another factor implicated in the response to nutritional status and a stimulus of lipogenesis, has also been reported to repress apoAV expression. Nowack et al (77) showed that insulin reduced both APOA5 mRNA levels and promoter activity in human primary hepatocytes and HepG2 cells. Moreover, these authors identified a molecular mechanism involving the upstream stimulatory factors 1 and 2 (USF1/USF2), which bind to an E-box located $-76 \mathrm{nt}$ in the APOA5 promoter. Insulin action subsequently leads to the activation of PI3K, which in turn phosphorylates USF1/USF2 and reduces binding to the apoAV E-box; this concerted mechanism leads to a decrease in apoAV transcription levels (Figure 2). The implication of USF1/USF2 in APOA5 gene expression is particularly interesting as USF corresponds to the gene on human chromosome 1q21-23 that is associated with familial combined hyperlipidemia and especially with elevated TG levels in men $(78,79)$. Finally, insulin infusion in human subjects led to reduction in circulating levels of apoAV protein (77). Thus, investigation of the regulation of APOA5 gene expression by insulin could help to 
understand the mechanistic basis of the elevated apoAV levels in patients with Type 2 diabetes. Indeed, in the context of hepatic insulin resistance, the inhibition of APOA5 expression by insulin may be altered, resulting in elevation of apoAV levels.

Thyroid hormones (thyroxine,T4; tri-iodothyronine, T3) are intimately involved in the metabolism of triglyceride-rich lipoproteins (80-83). Elevation of plasma TG concentration is associated with hypothyroidism in obese patients, who are characterized by attenuated rates of VLDL-TG clearance relative to those in obese euthyroid subjects (84). Such elevation in TG levels has been attributed to either low LPL $(85)$ or to low hepatic lipase activities $(86,87)$. The molecular mechanisms involved in the regulation of VLDL clearance by T4 remain to be defined however. Classically, T3 exerts its biological actions through binding to the nuclear thyroid hormone receptors $\alpha$ and $\beta$ (TR $\alpha$ and TR $\beta$ ). Recently, we have demonstrated that T3 treatment of human primary hepatocytes increases both APOA5 mRNA and protein levels (88). Furthermore, T3 regulates apoAV expression at the transcriptional level through the binding of TR to a DR4 element located at $-113 \mathrm{nt}$ of the APOA5 gene (Figure 2). In addition, we found that USF cooperates with TR, resulting in synergistic activation of the apoAV promoter in a ligand-dependent manner via an adjacent E-box motif. On the other hand, hypothyroid rats displayed low circulating levels of apoAV protein relative to controls, while administration of T3 restored apoAV protein abundance. In addition, one week of treatment with a single daily dose of the thyromimetic CGS-23425 increased hepatic levels of apoAV in fat-fed rats. Finally, this TR $\beta$ selective agonist induced a dramatic decrease in both VLDL-TG and total TG levels. Considered together, these results provide new insight into the low rates of VLDL-TG clearance and low LPL activity observed in hypothyroid patients. Furthermore, they emphasize the physiological role of TR in the regulation of genes involved in TG metabolism and confirm that TR $\beta$ may represent a potential pharmacological target for the treatment of hypertriglyceridemia.

In conclusion, the finding that apoAV is up-regulated by agonists of PPAR $\alpha, F X R$ and TR, which together constitute three distinct classes of hypotriglyceridemic ligands (Figure 1B), support the contention that apoAV plays a central role in the metabolism of VLDL and TRL.

\section{Conclusion}

In vitro structure-function studies, in vivo evaluation of apoAV function in geneticallymodified mouse models, together with characterization of clinical cases of patients carrying dysfunctional mutations, strongly support the contention that apoAV is a critical player in the 
regulation of plasma TG levels and in turn, of intravascular TRL metabolism. Nevertheless, further studies are needed not only to evaluate the role of apoAV in chylomicron and VLDL catabolism during the post-prandial phase, but also to assess the physiological relevance of apoAV transfer from HDL to VLDL postprandially. The positive association between plasma TG and apoAV levels observed in human subjects suggests however that there is a complex relationship between apoAV and TRL metabolism. Such a positive correlation was observed in dyslipidemic and in type 2 diabetic patients; by contrast, data in healthy subjects are contradictory. A positive correlation between plasma apoAV and TG concentrations has equally been reported recently in mice genetically deficient in apoAV, but which overexpress the human apoAV transgene. These findings highlight the possibility that APOA5 gene expression may respond to its metabolic environment, with potential upregulation in response to elevated TG levels. Upregulation of APOA5 expression by nuclear receptors such as PPARs, FXR, TR or alternatively its repression by lipogenic pathways mediated by insulin and SREBP1-C, suggests that complex transcriptional or translational regulations may occur under metabolic conditions in which elevated TG levels arise either independently of insulin resistance, or in association with it. Future studies should therefore focus on furthering our understanding as to whether elevation in circulating apoAV levels is a cause or a consequence of hypertriglyceridemia and/or of an insulin resistant state. Finally, the action of apoAV in the lipolysis of TRL in vivo under normal physiological conditions remains indeterminate. The answers to these topical questions will ultimately enable us to evaluate the potential of apoAV and apoAV-like peptides as therapeutic agents in hypertriglyceridemic states of either genetic and/or lifestyle and nutritional origin.

\section{Future perspective}

APOA5 gene expression is up-regulated by hypotriglyceridemic ligands, and even if incompletely characterized, the potential role of apoAV in TG metabolism appears to be unique. In mice, overexpression of apoCII, an obligatory co-activator of LPL, inhibits LPL activity as VLDL particles are less accessible to hydrolysis. In contrast, overexpression of apoAV in mice increases LPL activity. Several experimental findings tend to support the contention that apoAV does not modify post-heparin LPL activity and that its role in LPLmediated TRL hydrolysis is more complex, involving other factors. A better understanding of the implication of apoAV in TG hydrolysis is clearly a priority in future investigations of lipid and lipoprotein metabolism. 
ApoAV is an apolipoprotein of low abundance $(\sim 150 \mu \mathrm{g} / \mathrm{l})$ and its secretion is less efficient as compared to other apolipoproteins. ApoAV may therefore possess intra-cellular functions. The identification of an association of apoAV with lipid droplets in hepatic cells represents such a possibility. In addition, the association of apoAV with heparin and proteoglycans suggests that hepatic apoAV is secreted and then directly associates with the extra-cellular surface of the hepatocyte plasma membrane. Indeed, earlier studies showing an impairment of apoAV secretion involved analyses of the whole cell lysate, thereby precluding determination of intra-cellular and membrane-associated apoAV. Therefore, as suggested above, apoAV could be associated to LRP and SorLA and/or may interact with other factors implicated in lipoprotein metabolism such as hepatic lipase, which is known to be cell-membrane associated. Future studies that focus on the functional domains of apoAV implicated in its intra-cellular and cell-associated actions remain crucial to the overall understanding of the role of apoAV in lipid and lipoprotein metabolism. Indeed, such knowledge may open new horizons for the therapeutic normalization of metabolic diseases involving moderate to marked hypertriglyceridemia, and which are associated with accelerated atherosclerosis, such as the mixed hyperlipidemias of type 2 diabetes and the metabolic syndrome.

\section{Acknowledgments}

We thank Dr Herve Coste (GlaxoSmithKline) for critical discussion of the manuscript. 


\section{References}

1. Pennacchio LA, Olivier M, Hubacek JA, Cohen JC, Cox DR, Fruchart JC, Krauss RM, Rubin EM 2001 An apolipoprotein influencing triglycerides in humans and mice revealed by comparative sequencing. Science 294:169-73

2. van der Vliet HN, Sammels MG, Leegwater AC, Levels JH, Reitsma PH, Boers W, Chamuleau RA 2001 Apolipoprotein A-V: a novel apolipoprotein associated with an early phase of liver regeneration. J Biol Chem 276:44512-20

3. Pennacchio LA, Olivier M, Hubacek JA, Krauss RM, Rubin EM, Cohen JC 2002 Two independent apolipoprotein A5 haplotypes influence human plasma triglyceride levels. Hum Mol Genet 11:3031-8

4. Talmud PJ, Martin S, Taskinen MR, Frick MH, Nieminen MS, Kesaniemi YA, Pasternack A, Humphries SE, Syvanne M 2004 APOA5 gene variants, lipoprotein particle distribution, and progression of coronary heart disease: results from the LOCAT study. J Lipid Res 45:750-6

5. Ribalta J, Figuera L, Fernandez-Ballart J, Vilella E, Castro Cabezas M, Masana L, Joven J 2002 Newly identified apolipoprotein AV gene predisposes to high plasma triglycerides in familial combined hyperlipidemia. Clin Chem 48:1597-600

6. Schaap FG, Nierman MC, Berbee JF, Hattori H, Talmud PJ, Vaessen SF, Rensen PC, Chamuleau RA, Kuivenhoven JA, Groen AK 2006 Evidence for a complex relationship between apoA-V and apoC-III in patients with severe hypertriglyceridemia. J Lipid Res 47:2333-9

7. Talmud PJ, Cooper JA, Hattori H, Miller IP, Miller GJ, Humphries SE 2006 The apolipoprotein $\mathrm{A}-\mathrm{V}$ genotype and plasma apolipoprotein $\mathrm{A}-\mathrm{V}$ and triglyceride levels: prospective risk of type 2 diabetes. Results from the Northwick Park Heart Study II. Diabetologia 49:2337-40

8. Dallinga-Thie GM, van Tol A, Hattori H, van Vark-van der Zee LC, Jansen H, Sijbrands EJ 2006 Plasma apolipoprotein A5 and triglycerides in type 2 diabetes. Diabetologia 49:1505-11

9. Fruchart-Najib J, Bauge E, Niculescu LS, Pham T, Thomas B, Rommens C, Majd Z, Brewer B, Pennacchio LA, Fruchart JC 2004 Mechanism of triglyceride lowering in mice expressing human apolipoprotein A5. Biochem Biophys Res Commun 319:397404

10. Schaap FG, Rensen PC, Voshol PJ, Vrins C, van der Vliet HN, Chamuleau RA, Havekes LM, Groen AK, van Dijk KW 2004 ApoAV reduces plasma triglycerides by inhibiting very low density lipoprotein-triglyceride (VLDL-TG) production and stimulating lipoprotein lipase-mediated VLDL-TG hydrolysis. J Biol Chem 279:27941-7

11. Merkel M, Loeffler B, Kluger M, Fabig N, Geppert G, Pennacchio LA, Laatsch A, Heeren J 2005 Apolipoprotein AV accelerates plasma hydrolysis of triglyceride-rich lipoproteins by interaction with proteoglycan-bound lipoprotein lipase. J Biol Chem 280:21553-60

12. Brewer HB, Jr. 1999 Hypertriglyceridemia: changes in the plasma lipoproteins associated with an increased risk of cardiovascular disease. Am J Cardiol 83:3F-12F

13. Sarwar N, Danesh J, Eiriksdottir G, Sigurdsson G, Wareham N, Bingham S, Boekholdt SM, Khaw KT, Gudnason V 2007 Triglycerides and the risk of coronary heart disease: 10,158 incident cases among 262,525 participants in 29 Western prospective studies. Circulation 115:450-8

14. Austin MA, Hokanson JE, Edwards KL 1998 Hypertriglyceridemia as a cardiovascular risk factor. Am J Cardiol 81:7B-12B 
15. Weinberg RB, Cook VR, Beckstead JA, Martin DD, Gallagher JW, Shelness GS, Ryan RO 2003 Structure and interfacial properties of human apolipoprotein A-V. J Biol Chem 278:34438-44

16. Beckstead JA, Oda MN, Martin DD, Forte TM, Bielicki JK, Berger T, Luty R, Kay CM, Ryan RO 2003 Structure-function studies of human apolipoprotein A-V: a regulator of plasma lipid homeostasis. Biochemistry 42:9416-23

17. Beckstead JA, Wong K, Gupta V, Wan CP, Cook VR, Weinberg RB, Weers PM, Ryan RO 2007 The $\mathrm{C}$ terminus of apolipoprotein A-V modulates lipid-binding activity. J Biol Chem 282:15484-9

18. Prieur X, Coste H, Rodriguez JC 2003 The human apolipoprotein AV gene is regulated by peroxisome proliferator-activated receptor-alpha and contains a novel farnesoid X-activated receptor response element. J Biol Chem 278:25468-80

19. Dichlberger A, Cogburn LA, Nimpf J, Schneider WJ 2007 Avian apolipoprotein A-V binds to LDL receptor gene family members. J Lipid Res 48:1451-6

20. O'Brien PJ, Alborn WE, Sloan JH, Ulmer M, Boodhoo A, Knierman MD, Schultze AE, Konrad RJ 2005 The novel apolipoprotein A5 is present in human serum, is associated with VLDL, HDL, and chylomicrons, and circulates at very low concentrations compared with other apolipoproteins. Clin Chem 51:351-9

21. van der Vliet HN, Schaap FG, Levels JH, Ottenhoff R, Looije N, Wesseling JG, Groen AK, Chamuleau RA 2002 Adenoviral overexpression of apolipoprotein A-V reduces serum levels of triglycerides and cholesterol in mice. Biochem Biophys Res Commun 295:1156-9

22. Maeda N, Li H, Lee D, Oliver P, Quarfordt SH, Osada J 1994 Targeted disruption of the apolipoprotein C-III gene in mice results in hypotriglyceridemia and protection from postprandial hypertriglyceridemia. J Biol Chem 269:23610-6

23. Aalto-Setala K, Fisher EA, Chen X, Chajek-Shaul T, Hayek T, Zechner R, Walsh A, Ramakrishnan R, Ginsberg HN, Breslow JL 1992 Mechanism of hypertriglyceridemia in human apolipoprotein (apo) CIII transgenic mice. Diminished very low density lipoprotein fractional catabolic rate associated with increased apo CIII and reduced apo E on the particles. J Clin Invest 90:1889-900

24. Wang CS, McConathy WJ, Kloer HU, Alaupovic P 1985 Modulation of lipoprotein lipase activity by apolipoproteins. Effect of apolipoprotein C-III. J Clin Invest 75:38490

25. Lookene A, Beckstead JA, Nilsson S, Olivecrona G, Ryan RO 2005 Apolipoprotein A-V-heparin interactions: implications for plasma lipoprotein metabolism. J Biol Chem 280:25383-7

26. Sun G, Bi N, Li G, Zhu X, Zeng W, Wu G, Xue H, Chen B 2006 Identification of lipid binding and lipoprotein lipase activation domains of human apoAV. Chem Phys Lipids 143:22-8

27. Beigneux AP, Davies BS, Gin P, Weinstein MM, Farber E, Qiao X, Peale F, Bunting S, Walzem RL, Wong JS, Blaner WS, Ding ZM, Melford K, Wongsiriroj N, Shu X, de Sauvage F, Ryan RO, Fong LG, Bensadoun A, Young SG 2007 Glycosylphosphatidylinositol-anchored high-density lipoprotein-binding protein 1 plays a critical role in the lipolytic processing of chylomicrons. Cell Metab 5:279-91

28. Merkel M, Heeren J 2005 Give me A5 for lipoprotein hydrolysis! J Clin Invest 115:2694-6

29. Grosskopf I, Baroukh N, Lee SJ, Kamari Y, Harats D, Rubin EM, Pennacchio LA, Cooper AD 2005 Apolipoprotein A-V deficiency results in marked hypertriglyceridemia attributable to decreased lipolysis of triglyceride-rich lipoproteins and removal of their remnants. Arterioscler Thromb Vasc Biol 25:2573-9 
30. Nilsson SK, Lookene A, Beckstead JA, Gliemann J, Ryan RO, Olivecrona G 2007 Apolipoprotein A-V interaction with members of the low density lipoprotein receptor gene family. Biochemistry 46:3896-904

31. Shu X, Chan J, Ryan RO, Forte TM 2007 Apolipoprotein A-V association with intracellular lipid droplets. J Lipid Res 48:1445-50

32. Lai CQ, Parnell LD, Ordovas JM 2005 The APOA1/C3/A4/A5 gene cluster, lipid metabolism and cardiovascular disease risk. Curr Opin Lipidol 16:153-66

33. van Dijk KW, Rensen PC, Voshol PJ, Havekes LM 2004 The role and mode of action of apolipoproteins CIII and AV: synergistic actors in triglyceride metabolism? Curr Opin Lipidol 15:239-46

34. Pennacchio LA, Rubin EM 2003 Apolipoprotein A5, a newly identified gene that affects plasma triglyceride levels in humans and mice. Arterioscler Thromb Vasc Biol 23:529-34

35. Henneman P, Schaap FG, Havekes LM, Rensen PC, Frants RR, van Tol A, Hattori H, Smelt AH, van Dijk KW 2007 Plasma apoAV levels are markedly elevated in severe hypertriglyceridemia and positively correlated with the APOA5 S19W polymorphism. Atherosclerosis 193:129-34

36. Martinelli N, Trabetti E, Bassi A, Girelli D, Friso S, Pizzolo F, Sandri M, Malerba G, Pignatti PF, Corrocher R, Olivieri O 2007 The -1131 T $>$ C and S19W APOA5 gene polymorphisms are associated with high levels of triglycerides and apolipoprotein $\mathrm{C}$ III, but not with coronary artery disease: an angiographic study. Atherosclerosis 191:409-17

37. Talmud PJ, Hawe E, Martin S, Olivier M, Miller GJ, Rubin EM, Pennacchio LA, Humphries SE 2002 Relative contribution of variation within the APOC3/A4/A5 gene cluster in determining plasma triglycerides. Hum Mol Genet 11:3039-46

38. Talmud PJ, Palmen J, Putt W, Lins L, Humphries SE 2005 Determination of the functionality of common APOA5 polymorphisms. J Biol Chem 280:28215-20

39. Ahituv N, Akiyama J, Chapman-Helleboid A, Fruchart J, Pennacchio LA 2007 In vivo characterization of human APOA5 haplotypes. Genomics 90:674-9

40. Elosua R, Ordovas JM, Cupples LA, Lai CQ, Demissie S, Fox CS, Polak JF, Wolf PA, D'Agostino RB, Sr., O'Donnell CJ 2006 Variants at the APOA5 locus, association with carotid atherosclerosis, and modification by obesity: the Framingham Study. J Lipid Res 47:990-6

41. Choi JR, Nam CM, Kang DR, Eom SM, Lee HJ, Park CM, Im JW, Jang Y 2007 DNA Polymorphisms and Haplotypes of Apolipoprotein A5's Attribution to the Plasma Triglyceride Levels in Koreans. Yonsei Med J 48:609-18

42. Jiang YD, Yen CJ, Chou WL, Kuo SS, Lee KC, Chiu KC, Chuang LM 2005 Interaction of the G182C polymorphism in the APOA5 gene and fasting plasma glucose on plasma triglycerides in Type 2 diabetic subjects. Diabet Med 22:1690-5

43. Talmud PJ 2007 Rare APOA5 mutations--clinical consequences, metabolic and functional effects: an ENID review. Atherosclerosis 194:287-92

44. Oliva CP, Pisciotta L, Li Volti G, Sambataro MP, Cantafora A, Bellocchio A, Catapano A, Tarugi P, Bertolini S, Calandra S 2005 Inherited apolipoprotein A-V deficiency in severe hypertriglyceridemia. Arterioscler Thromb Vasc Biol 25:411-7

45. Marcais C, Verges B, Charriere S, Pruneta V, Merlin M, Billon S, Perrot L, Drai J, Sassolas A, Pennacchio LA, Fruchart-Najib J, Fruchart JC, Durlach V, Moulin P 2005 Apoa5 Q139X truncation predisposes to late-onset hyperchylomicronemia due to lipoprotein lipase impairment. J Clin Invest 115:2862-9 
46. Priore Oliva C, Carubbi F, Schaap FG, Bertolini S, Calandra S 2008

Hypertriglyceridaemia and low plasma HDL in a patient with apolipoprotein A-V deficiency due to a novel mutation in the APOA5 gene. J Intern Med 263:450-8

47. Pruneta-Deloche V, Ponsin G, Groisne L, Fruchart-Najib J, Lagarde M, Moulin P 2005 Postprandial increase of plasma apoAV concentrations in Type 2 diabetic patients. Atherosclerosis 181:403-5

48. Nelbach L, Shu X, Konrad RJ, Ryan RO, Forte TM 2007 Effect of apolipoprotein A-V on plasma triglyceride, lipoprotein size and composition in genetically engineered mice. J Lipid Res

49. Kahri J, Fruchart-Najib J, Matikainen N, Fruchart JC, Vakkilainen J, Taskinen MR 2007 The increase of apolipoprotein A-V during postprandial lipemia parallels the response of triglyceride-rich lipoproteins in type 2 diabetes: no relationship between apoA-V and postheparin plasma lipolytic activity. Diabetes Care 30:2083-5

50. Moreno-Luna R, Perez-Jimenez F, Marin C, Perez-Martinez P, Gomez P, JimenezGomez Y, Delgado-Lista J, Moreno JA, Tanaka T, Ordovas JM, Lopez-Miranda J 2007 Two independent apolipoprotein A5 haplotypes modulate postprandial lipoprotein metabolism in a healthy Caucasian population. J Clin Endocrinol Metab 92:2280-5

51. Kim JY, Kim OY, Koh SJ, Jang Y, Yun SS, Ordovas JM, Lee JH 2006 Comparison of low-fat meal and high-fat meal on postprandial lipemic response in non-obese men according to the $-1131 \mathrm{~T}>\mathrm{C}$ polymorphism of the apolipoprotein A5 (APOA5) gene (randomized cross-over design). J Am Coll Nutr 25:340-7

52. Staels B, Dallongeville J, Auwerx J, Schoonjans K, Leitersdorf E, Fruchart JC 1998 Mechanism of action of fibrates on lipid and lipoprotein metabolism. Circulation 98:2088-93

53. Auwerx J 1992 Regulation of gene expression by fatty acids and fibric acid derivatives: an integrative role for peroxisome proliferator activated receptors. The Belgian Endocrine Society Lecture 1992. Horm Res 38:269-77

54. Kersten S, Desvergne B, Wahli W 2000 Roles of PPARs in health and disease. Nature 405:421-4

55. Rodriguez JC, Gil-Gomez G, Hegardt FG, Haro D 1994 Peroxisome proliferatoractivated receptor mediates induction of the mitochondrial 3-hydroxy-3methylglutaryl-CoA synthase gene by fatty acids. J Biol Chem 269:18767-72

56. Schoonjans K, Staels B, Auwerx J 1996 Role of the peroxisome proliferator-activated receptor (PPAR) in mediating the effects of fibrates and fatty acids on gene expression. J Lipid Res 37:907-25

57. Tugwood JD, Issemann I, Anderson RG, Bundell KR, McPheat WL, Green S 1992 The mouse peroxisome proliferator activated receptor recognizes a response element in the 5' flanking sequence of the rat acyl CoA oxidase gene. Embo J 11:433-9

58. Schoonjans K, Staels B, Grimaldi P, Auwerx J 1993 Acyl-CoA synthetase mRNA expression is controlled by fibric-acid derivatives, feeding and liver proliferation. Eur J Biochem 216:615-22

59. Frenkel B, Mayorek N, Hertz R, Bar-Tana J 1988 The hypochylomicronemic effect of beta,beta'-methyl-substituted hexadecanedioic acid (MEDICA 16) is mediated by a decrease in apolipoprotein C-III. J Biol Chem 263:8491-7

60. Hertz R, Bishara-Shieban J, Bar-Tana J 1995 Mode of action of peroxisome proliferators as hypolipidemic drugs. Suppression of apolipoprotein C-III. J Biol Chem 270:13470-5

61. Schoonjans K, Peinado-Onsurbe J, Lefebvre AM, Heyman RA, Briggs M, Deeb S, Staels B, Auwerx J 1996 PPARalpha and PPARgamma activators direct a distinct 
tissue-specific transcriptional response via a PPRE in the lipoprotein lipase gene. Embo J 15:5336-48

62. Coste H, Rodriguez JC 2002 Orphan nuclear hormone receptor Rev-erbalpha regulates the human apolipoprotein CIII promoter. J Biol Chem 277:27120-9

63. Vu-Dac N, Gervois P, Jakel H, Nowak M, Bauge E, Dehondt H, Staels B, Pennacchio LA, Rubin EM, Fruchart-Najib J, Fruchart JC 2003 Apolipoprotein A5, a crucial determinant of plasma triglyceride levels, is highly responsive to peroxisome proliferator-activated receptor alpha activators. J Biol Chem 278:17982-5

64. Schultze AE, Alborn WE, Newton RK, Konrad RJ 2005 Administration of a PPARalpha agonist increases serum apolipoprotein A-V levels and the apolipoprotein A-V/apolipoprotein C-III ratio. J Lipid Res 46:1591-5

65. Dorfmeister B, Brandlhofer S, Schaap FG, Hermann M, Furnsinn C, Hagerty BP, Stangl H, Patsch W, Strobl W 2006 Apolipoprotein AV does not contribute to hypertriglyceridaemia or triglyceride lowering by dietary fish oil and rosiglitazone in obese Zucker rats. Diabetologia 49:1324-32

66. Lai CQ, Arnett DK, Corella D, Straka RJ, Tsai MY, Peacock JM, Adiconis X, Parnell LD, Hixson JE, Province MA, Ordovas JM 2007 Fenofibrate effect on triglyceride and postprandial response of apolipoprotein A5 variants: the GOLDN study. Arterioscler Thromb Vasc Biol 27:1417-25

67. Claudel T, Leibowitz MD, Fievet C, Tailleux A, Wagner B, Repa JJ, Torpier G, Lobaccaro JM, Paterniti JR, Mangelsdorf DJ, Heyman RA, Auwerx J 2001 Reduction of atherosclerosis in apolipoprotein E knockout mice by activation of the retinoid $\mathrm{X}$ receptor. Proc Natl Acad Sci U S A 98:2610-5

68. Stedman C, Liddle C, Coulter S, Sonoda J, Alvarez JG, Evans RM, Downes M 2006 Benefit of farnesoid X receptor inhibition in obstructive cholestasis. Proc Natl Acad Sci U S A 103:11323-8

69. Huang W, Ma K, Zhang J, Qatanani M, Cuvillier J, Liu J, Dong B, Huang X, Moore DD 2006 Nuclear receptor-dependent bile acid signaling is required for normal liver regeneration. Science 312:233-6

70. Zannis VI, Kan HY, Kritis A, Zanni E, Kardassis D 2001 Transcriptional regulation of the human apolipoprotein genes. Front Biosci 6:D456-504

71. Prieur X, Schaap FG, Coste H, Rodriguez JC 2005 Hepatocyte nuclear factor-4alpha regulates the human apolipoprotein AV gene: identification of a novel response element and involvement in the control by peroxisome proliferator-activated receptorgamma coactivator-1alpha, AMP-activated protein kinase, and mitogen-activated protein kinase pathway. Mol Endocrinol 19:3107-25

72. Genoux A, Dehondt H, Helleboid-Chapman A, Duhem C, Hum DW, Martin G, Pennacchio LA, Staels B, Fruchart-Najib J, Fruchart JC 2005 Transcriptional regulation of apolipoprotein A5 gene expression by the nuclear receptor RORalpha. Arterioscler Thromb Vasc Biol 25:1186-92

73. Lind U, Nilsson T, McPheat J, Stromstedt PE, Bamberg K, Balendran C, Kang D 2005 Identification of the human ApoAV gene as a novel RORalpha target gene. Biochem Biophys Res Commun 330:233-41

74. Jakel H, Nowak M, Moitrot E, Dehondt H, Hum DW, Pennacchio LA, Fruchart-Najib J, Fruchart JC 2004 The liver X receptor ligand T0901317 down-regulates APOA5 gene expression through activation of SREBP-1c. J Biol Chem 279:45462-9

75. Sone H, Shimano H, Sakakura Y, Inoue N, Amemiya-Kudo M, Yahagi N, Osawa M, Suzuki H, Yokoo T, Takahashi A, Iida K, Toyoshima H, Iwama A, Yamada N 2002 Acetyl-coenzyme A synthetase is a lipogenic enzyme controlled by SREBP-1 and energy status. Am J Physiol Endocrinol Metab 282:E222-30 
76. Yahagi N, Shimano H, Hasty AH, Amemiya-Kudo M, Okazaki H, Tamura Y, lizuka Y, Shionoiri F, Ohashi K, Osuga J, Harada K, Gotoda T, Nagai R, Ishibashi S, Yamada N 1999 A crucial role of sterol regulatory element-binding protein-1 in the regulation of lipogenic gene expression by polyunsaturated fatty acids. J Biol Chem 274:35840-4

77. Nowak M, Helleboid-Chapman A, Jakel H, Martin G, Duran-Sandoval D, Staels B, Rubin EM, Pennacchio LA, Taskinen MR, Fruchart-Najib J, Fruchart JC 2005 Insulinmediated down-regulation of apolipoprotein A5 gene expression through the phosphatidylinositol 3-kinase pathway: role of upstream stimulatory factor. Mol Cell Biol 25:1537-48

78. Shoulders CC, Naoumova RP 2004 USF1 implicated in the aetiology of familial combined hyperlipidaemia and the metabolic syndrome. Trends Mol Med 10:362-5

79. Pajukanta P, Lilja HE, Sinsheimer JS, Cantor RM, Lusis AJ, Gentile M, Duan XJ, Soro-Paavonen A, Naukkarinen J, Saarela J, Laakso M, Ehnholm C, Taskinen MR, Peltonen L 2004 Familial combined hyperlipidemia is associated with upstream transcription factor 1 (USF1). Nat Genet 36:371-6

80. O'Hara DD, Porte D, Jr., Williams RH 1966 The effect of diet and thyroxin on plasma lipids in myxedema. Metabolism 15:123-34

81. Abrams JJ, Grundy SM, Ginsberg H 1981 Metabolism of plasma triglycerides in hypothyroidism and hyperthyroidism in man. J Lipid Res 22:307-22

82. O'Brien T, Dinneen SF, O'Brien PC, Palumbo PJ 1993 Hyperlipidemia in patients with primary and secondary hypothyroidism. Mayo Clin Proc 68:860-6

83. Pykalisto O, Goldberg AP, Brunzell JD 1976 Reversal of decreased human adipose tissue lipoprotein lipase and hypertriglyceridemia after treatment of hypothyroidism. $\mathrm{J}$ Clin Endocrinol Metab 43:591-600

84. Ginsberg HN 1998 Lipoprotein physiology. Endocrinol Metab Clin North Am 27:50319

85. Porte D, Jr., O'Hara DD, Williams RH 1966 The relation between postheparin lipolytic activity and plasma triglyceride in myxedema. Metabolism 15:107-13

86. Ito M, Takamatsu J, Matsuo T, Kameoka K, Kubota S, Fukata S, Tamai H, Miyauchi A, Kuma K, Hanafusa T 2003 Serum concentrations of remnant-like particles in hypothyroid patients before and after thyroxine replacement. Clin Endocrinol (Oxf) 58:621-6

87. Tan KC, Shiu SW, Kung AW 1998 Effect of thyroid dysfunction on high-density lipoprotein subfraction metabolism: roles of hepatic lipase and cholesteryl ester transfer protein. J Clin Endocrinol Metab 83:2921-4

88. Prieur X, Huby T, Coste H, Schaap FG, Chapman MJ, Rodriguez JC 2005 Thyroid hormone regulates the hypotriglyceridemic gene APOA5. J Biol Chem 280:27533-43 


\section{Figure Legends}

Figure 1: Mechanism of action of apoAV on TG levels. (1A) TG-rich lipoproteins are hydrolyzed by LPL under the influence of specific apolipoproteins. ApoCII is an obligatory cofactor and apoCIII inhibits LPL activity. Recently, apoAV has been shown to positively regulate HSPG-bound LPL either by direct interaction or through interaction with proteoglycans. In addition, apoAV, by interacting with the LDL receptor-related protein (LRP1) and the mosaic type-1 receptor (SorLA), facilitates TRL remnant uptake.

In figure $1 \mathrm{~B}$, pharmacological regulation of apoAV expression is represented and directly linked to LPL activity. Fibrates inversely regulate apoAV and apoCIII expression levels and lead to enhanced LPL activity.

Figure 2: Schematic representation of the human APOA5 promoter region and transcription factor binding sites. Homodimers and heterodimers of transcription factors bind to these motifs to modulate human APOA5 gene expression. 


\section{Hepatocyte}

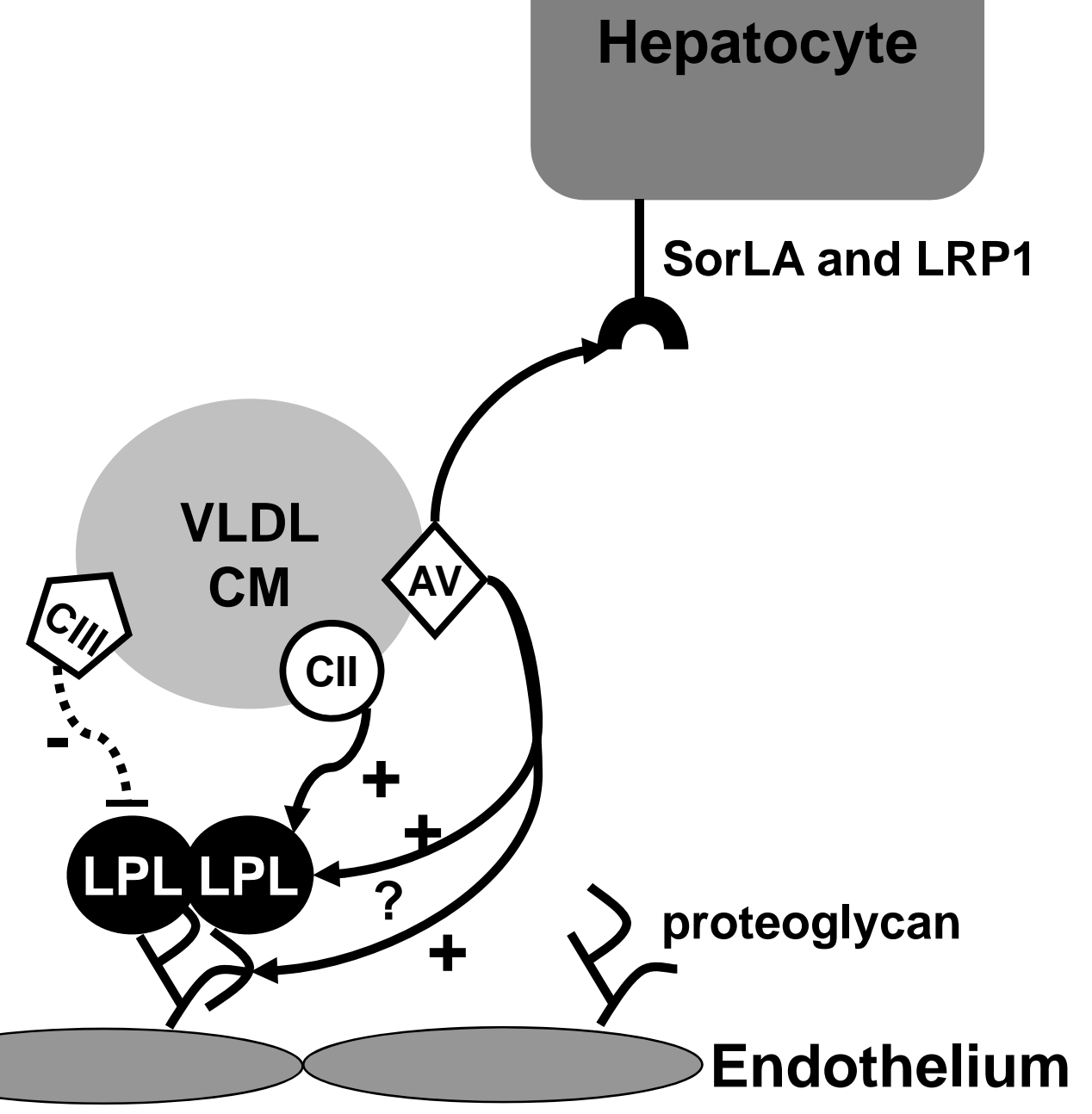

Figure $1 \mathrm{~A}$ 


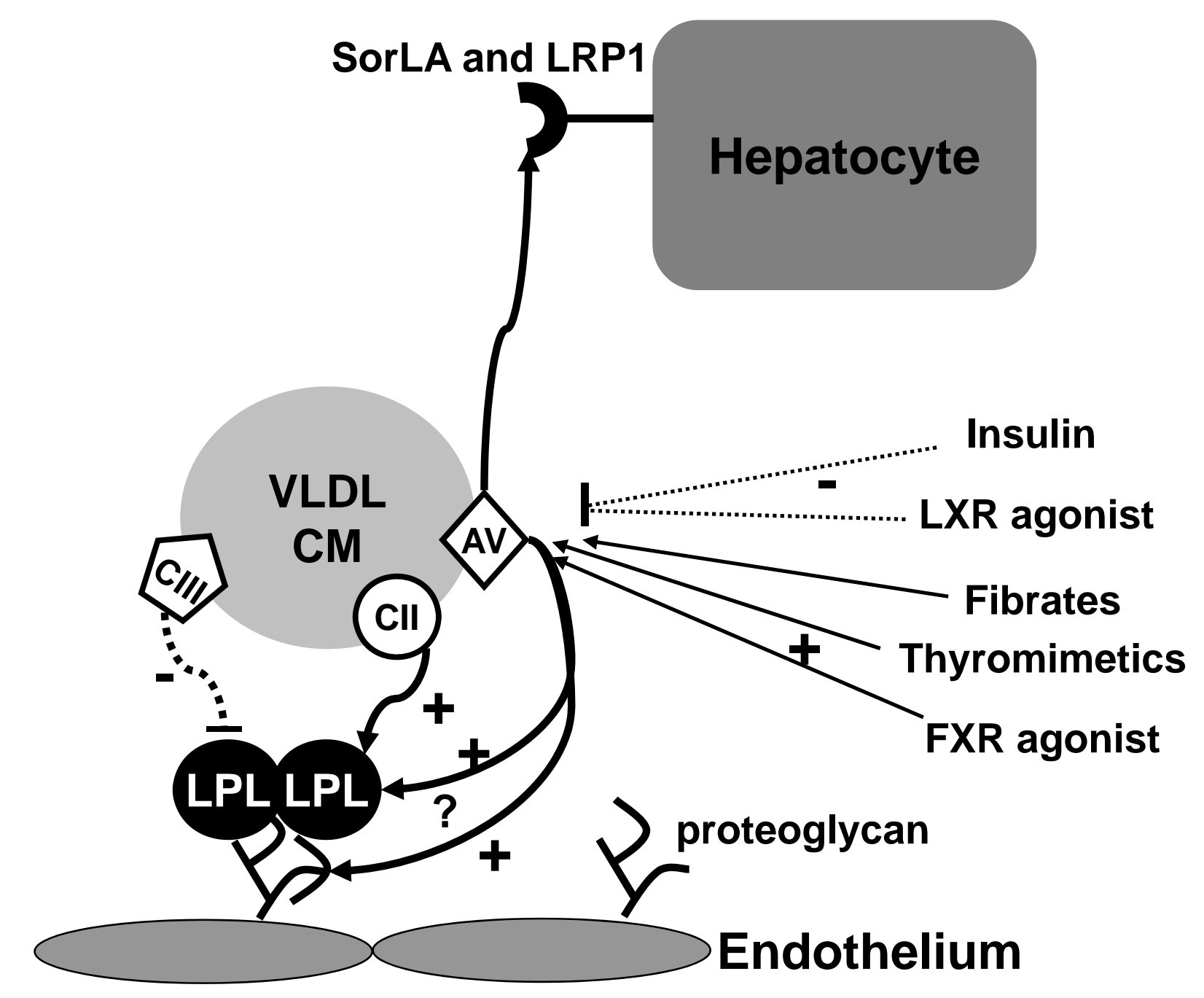

Figure 1B 


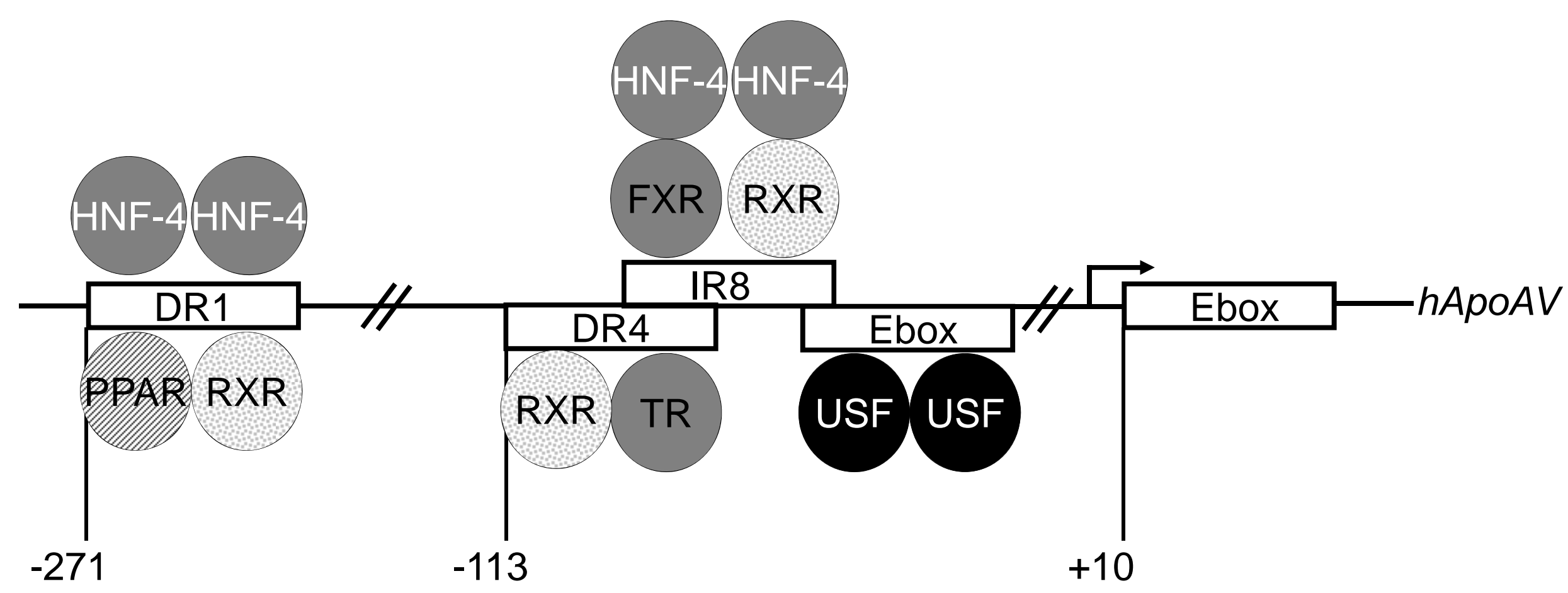

Figure 2 